\title{
Orthopteroids in Kaziranga National Park, Assam, India
}

\author{
N. Senthilkumar
}

Rain Forest Research Institute, P.O. Box No. 136, A.T. Road (East), Jorhat, Assam 785 001, India Present Address: Institute of Forest Genetics and Tree Breeding, Coimbatore, Tamilnadu, India Email: senthilnk@icfre.org

\begin{abstract}
Thirty-six species of orthopteroids belonging to 30 genera, and four families were recorded in different habitats viz., forestlands, savannahs and grasslands of the Kaziranga Nationa Park (KNP) at Assam. The observations were recorded during the period of three years from January 2007 to December 2009, by periodical monthly visits to Kohora range (central range), Baguri range (western range) and Agoratoli range (eastern range) based on the habitat types selected. The family Acrididae had the largest species representation (19 species) followed by Tettigoniidae (nine species) and Mantidae (five species) while Gryllidae was represented by three species only. None of the species found in the study area are known to be threatened under any category of IUCN, 2010.
\end{abstract}

Key words: Acrididae, Biodiversity, Gryllidae, Mantidae, Orthoptera, Tettigoniidae.

The Kaziranga National Park (KNP), over an area of $430 \mathrm{~km}^{2}$ and bounded by the Mikir Hills on the south and the Brahmputra River on the north lies between $26^{\circ} 30^{\prime}$ $26^{\circ} 45^{\prime} \mathrm{N}$ \& $93^{\circ} 08^{\prime}-93^{\circ} 36^{\prime} \mathrm{E}$ within two districts - Nagaon and Golaghat, in the Indian state of Assam. The KNP is approximately $40 \mathrm{~km}$ from east to west, and $13 \mathrm{~km}$ from north to south with elevation ranging from 40 to $80 \mathrm{~m}$ above sea level. Average temperature ranges from 5 to $37^{\circ} \mathrm{C}$ and average humidity ranges between $65 \%$ and

Date of publication (online): 26 September 2010

Date of publication (print): 26 September 2010

ISSN 0974-7907 (online) | 0974-7893 (print)

Editor: Nitin Kulkarni

\section{Manuscript details:}

Ms \# 02437

Received 07 April 2010

Final received 16 August 2010

Finally accepted 23 August 2010

Citation: Senthilkumar, N. (2010). Orthopteroids in Kaziranga National Park, Assam, India. Journal of Threatened Taxa 2(10): 1227-1231.

Copyright: (c) N. Senthilkumar 2010. Creative Commons Attribution 3.0 Unported License. JoTT allows unrestricted use of this article in any medium for non-profit purposes, reproduction and distribution by providing adequate credit to the authors and the source of publication.

Acknowledgements: Author is grateful to the Ministry of Environment and Forests, Govt. of India for the financial support through the project No. 14/25/2005-ESR/RE dt.25.08.2006, the Director, RFRI, Jorhat for facilities and the Forest Department, Assam State for permission to work in the Sanctuary.

\section{OPEN ACCESS | FREE DOWNLOAD (C) (i) (4)}

$95 \%$. Rainy season is May to October, and the annual rainfall is about $2500 \mathrm{~mm}$.

The four main types of vegetation, alluvial inundated grasslands, alluvial savanna woodlands, tropical moist mixed deciduous forests, and tropical semi-evergreen forests exist in the park. There is a decline in altitude from the east to west. The western reaches are dominated by grasslands. Tall elephant grass is found on higher ground, while short grasses cover the lower grounds. Common tall grasses are spear grass, elephant grass, and the common reed. Numerous forbs are present along with the grasses. Amidst the grasses, providing cover and shade are scattered trees-dominant species including Kumbhi, Indian Gooseberry, The Cotton Tree (in savanna woodlands), and Elephant Apple (in inundated grasslands). Thick evergreen forests have trees of Aphanamixis polystachya, Talauma hodgsonii, Dillenia indica, Garcinia tinctoria, Ficus rumphii, Cinnamomum bejolghota, and species of Syzygium. Tropical semievergreen forests have Albizia procera, Duabanga grandiflora, Lagerstroemia speciosa, Crateva unilocularis, Sterculia urens, Grewia serrulata, Mallotus philippensis, Bridelia retusa, Aphania rubra, Leea indica, and Leea umbraculifera. An invasive species, Mimosa invisa, which is toxic to herbivores is found in the park (UNEP-WCMC, 2009).

The KNP, home to the world's largest population of the Great Indian One-Horned Rhinoceros, Wild Asiatic Water Buffalo and Eastern Swamp Deer has significant breeding populations of 35 mammalian species, of which 15 are threatened as per IUCN Red List. It also has the highest density of tigers in the world ( 1 per $5 \mathrm{~km}^{2}$ ), with a population of 86 , as per the latest census. Nine of the 14 primates of India, and the only ape, the Hoolock Gibbon (UNEP-WCMC 2009) occur in the park. Most of the forest areas $\left(51.14 \mathrm{~km}^{2}\right)$ have eroded due to perennial rains and flooding in the Brahmaputra with loss of biodiversity. There is no authentic record on the insect fauna of The Kaziranga National Park, and hence this initial step, on inventorying the Orthoptera fauna of the park.

\section{Methods}

Diverse habitats in KNP, were surveyed monthly, for assessing the distribution and diversity of Orthoptera, from January 2007 to December 2009. Three habitat types representing forestlands, savannahs and grasslands 
Table 1. Habitat-wise distribution of Orthoptera and Mantodea in Kaziranga National Park, Assam

\begin{tabular}{|c|c|c|c|c|c|}
\hline Sno & Species & Family & Forest & Savannah & Grassland \\
\hline 1 & Xenocatantops humilis (Serv.) & Acrididae & + & + & + \\
\hline 2 & Phlaeoba infumata Brun. & Acrididae & + & + & + \\
\hline 3 & Phlaeoba tenebrosa (Walk.) & Acrididae & - & + & + \\
\hline 4 & Spathosternum prasiniferum (Walk.) & Acrididae & + & - & - \\
\hline 5 & Atractomorpha crenulata (Fab.) & Acrididae & - & + & + \\
\hline 6 & Catantops ferruginuous (Walk.) & Acrididae & + & + & + \\
\hline 7 & Gesonula punctifrons (Stal.) & Acrididae & - & + & + \\
\hline 8 & Phlaeoba antennata Brunner von Wattenwy & Acrididae & + & - & - \\
\hline 9 & Phlaeoba sp. & Acrididae & - & + & - \\
\hline 10 & Trilophidia annulata (Thunb.) & Acrididae & + & - & - \\
\hline 11 & Caryanda sp. & Acrididae & + & - & - \\
\hline 12 & Atractomorpha sp. & Acrididae & - & + & + \\
\hline 13 & Tagasta indica Bolívar & Acrididae & + & - & - \\
\hline 14 & Oxya hyla hyla (Serv.) & Acrididae & - & - & + \\
\hline 15 & Heiroglyphus banian (Fab.) & Acrididae & - & + & + \\
\hline 16 & Eyprepocnemis alacris (Serv.) & Acrididae & - & + & + \\
\hline 17 & Orthacris maindroni Bol. & Acrididae & - & + & + \\
\hline 18 & Acrida exaltata (Walk.) & Acrididae & - & + & + \\
\hline 19 & Oxya nitidula (Walk.) & Acrididae & - & - & + \\
\hline 20 & Conocephalus maculatus (Le Guillou) & Tettigoniidae & + & + & + \\
\hline 21 & Conocephalus (Xiphidion) melaenus (De Haan) & Tettigoniidae & + & - & - \\
\hline 22 & Euconocephalus indicus (Redtenb.) & Tettigoniidae & - & + & + \\
\hline 23 & Letana rubescens (Stål) & Tettigoniidae & + & - & - \\
\hline 24 & Hexacentrus unicolor Serville. & Tettigoniidae & + & + & - \\
\hline 25 & Khaoyaiana sp. & Tettigoniidae & + & - & - \\
\hline 26 & Hexacentrus major Redtenb. & Tettigoniidae & + & - & - \\
\hline 27 & Elimaea (Orthelimaea) securigera (Brun.) & Tettigoniidae & + & + & + \\
\hline 28 & Mirrollia sp. & Tettigoniidae & - & - & + \\
\hline 29 & Teleogryllus sp. & Gryllidae & - & + & + \\
\hline 30 & Gryllinae sp. & Gryllidae & + & - & - \\
\hline 31 & Gryllodes sigillatus (Walk.) & Gryllidae & + & + & + \\
\hline 32 & Hierodula sp. & Mantidae & - & + & - \\
\hline 33 & Creobroter sp. & Mantidae & + & - & - \\
\hline 34 & Statilia sp. & Mantidae & - & - & + \\
\hline 35 & Tenodera sp. & Mantidae & - & + & + \\
\hline 36 & Mantodea sp. & Mantidae & + & - & - \\
\hline
\end{tabular}

+ - Presence; - - Absence

were chosen at Kohora range (central range), Baguri range (western range) and Agoratoli range (eastern range) respectively.

Inventorying protocol: Representative habitat types were selected and survey plots were laid. Each survey plot was divided into quadrates measuring $10 \times 10 \mathrm{~m}$ each and five such were chosen for random sampling. The ground level vegetation was searched, by hand picking the insects from the vegetation, sweep nets were deployed for collecting samples. This exercise was carried out from 0600 to $0800 \mathrm{hr}$. and repeated from 1800 to $2000 \mathrm{hr}$. to enumerate the nocturnal species. The evening sampling was supplemented with a light trap i.e., a portable light trap following Sanjayan (1994) for Orthoptera. Collected specimens were narcotized with menthol (Naphthalene) crystals and brought into the laboratory, air-dried for preservation as per standard procedures and identification. Specimens collected were 
identified following Rentz (1979), Naskrecki (1994, 1996 a,b, 2000), Ingrisch \& Shishodia (1997, 1998, 2000), Shishodia (2000a, b), and Senthilkumar et al. (2001, 2002).

Data analysis: Shannon's diversity index $\left(\mathrm{H}^{\prime}\right)$ was calculated since it is well accepted that all species at a site, within and across systematic groups contribute equally to its biodiversity (Ganeshaiah et al. 1997). In addition, Simpson's diversity index $(\lambda)$ as per Ludwig \& Reynolds (1988) and coverage estimators were also calculated using the EstimateS software of Colwell (2004).

\section{Results and Discussion}

A total of 36 species of orthopteroids belonging to 30 genera, and four families was recorded from different habitats viz., forestlands, savannahs and grasslands of Kaziranga National Park during the survey period (Table 1). The Family Acrididae had the largest species representation (19 species) followed by Tettigoniidae (nine species) and Mantidae (five species) while Gryllidae was represented by three species only (Fig. 1). Short-horned Grasshoppers were recorded with greater diversity in all the habitats. Grasslands harboured greater number of Orthoptera species (21 species) followed by savannahs (20 species) and forestlands (19 species) (Fig. 2). Four Orthopteran species namely Xenocatantops humilis (Serv.), Phlaeoba infumata Brun., Catantops ferruginuous (Walk.) and Conocephalus maculatus (Le Guilou) were commonly observed in almost all the habitats. Seventeen species were encountered in both savannahs and grasslands followed by seven species in both forestlands and savannahs and six species in both forestlands and grasslands. Spathosternum prasiniferum (Walk.), Phlaeoba antennata Brunner von Wattenwyl, Trilophidia annulata (Thunb.), Caryanda sp., Tagasta indica Bolívar, Conocephalus (Xiphidion) melaenus (De Haan), Letana rubescens (Stål), Khaoyaiana sp., Hexacentrus major Redtenb., Gryllinae sp., Creobroter sp. and Mantodea $\mathrm{sp}$. were recorded only in forests, while Hierodula sp. and Phlaeoba sp. were encountered in savannahs alone. A greater diversity of short-horned grasshoppers was recorded in all the habitats viz., grasslands, savannahs and forestlands in KNP. This conforms to the host plant distribution hypothesis (Cornell \& Lawton 1992). Orthoptera diversity is related to the ecosystem, the grassland and savannah habitats facilitating greater species inhabitation (Senthilkumar et al. 2009). Grasshoppers capable of feeding on grasses in spite of high silica content (Chand \& Muralirangan 2006) take refuge in the grasslands. Heterogeneous conditions form the basis of a stable and well-balanced environment in which populations of orthopterans oscillate within certain limits (Senthilkumar et al. 2006). This observation is in consonance with the study of acridid diversity in Tamilnadu (Senthilkumar et al. 2009). The finding of uniqueness of certain species in particular habitats suggested that

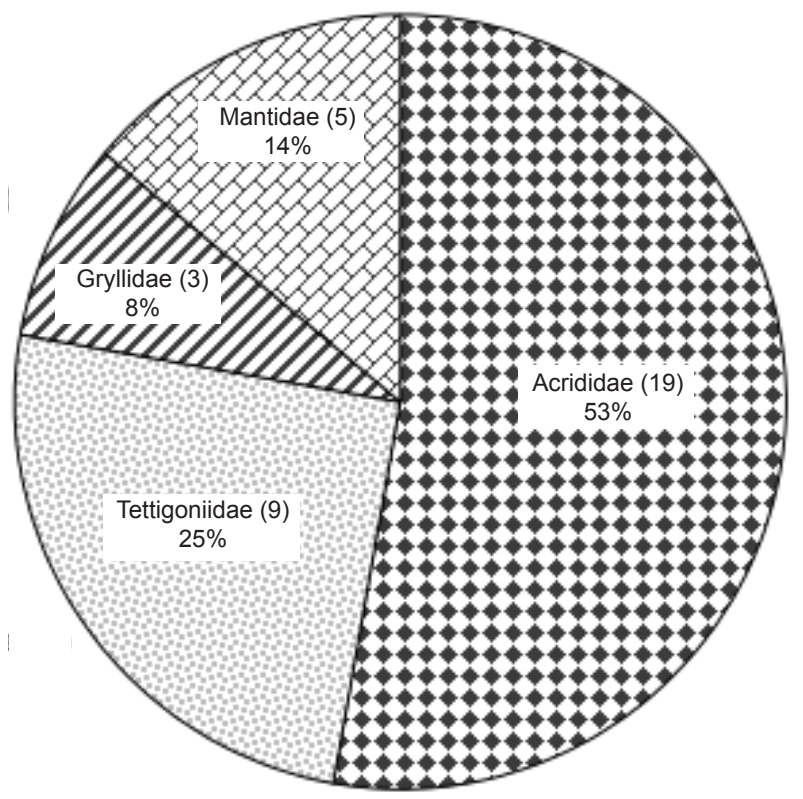

Figure 1. Orthopteroid faunal composiion in Kaziranga National Park, Assam

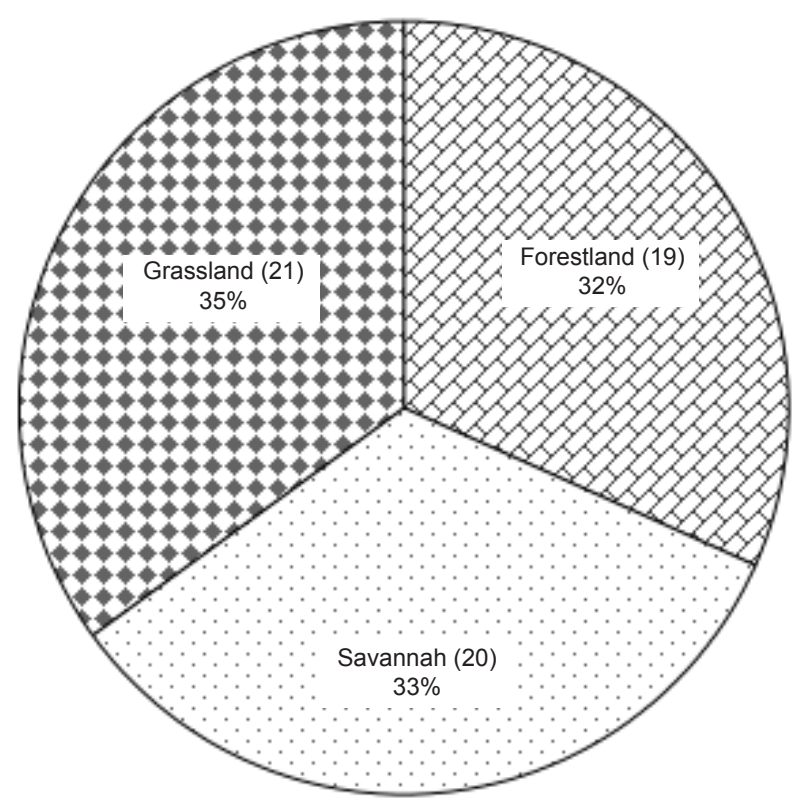

Figure 2. Orthopteroid species richness with reference to habitat types in Kaziranga National Park, Assam

most of the grasshoppers are highly selective to host plants or habitats as Mulkern (1967) reported. Oxya hyla hyla (Serv.), Oxya nitidula (Walk.) and Statilia sp. were represented only in the grasslands.

As a measure of diversity within a habitat, Fisher's alpha, and Shannon's diversity indices were calculated. Fisher's a index indicates richness of the Orthopteran species in descending order from the forests, the grasslands, and lastly the savannahs. The diversity 


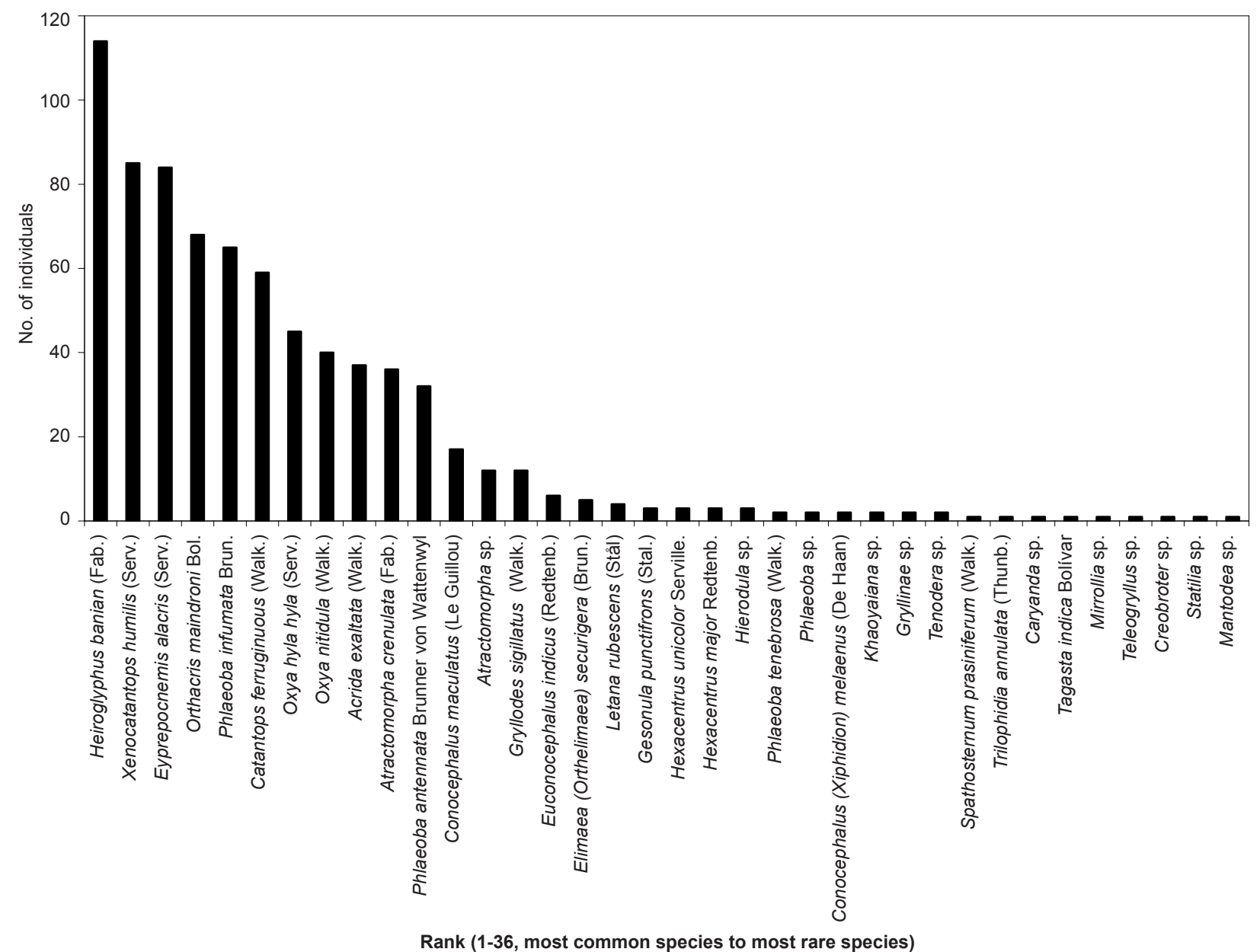

Figure 3. Log series distribution pattern of orthopteroids in Kaziranga National Park, Assam

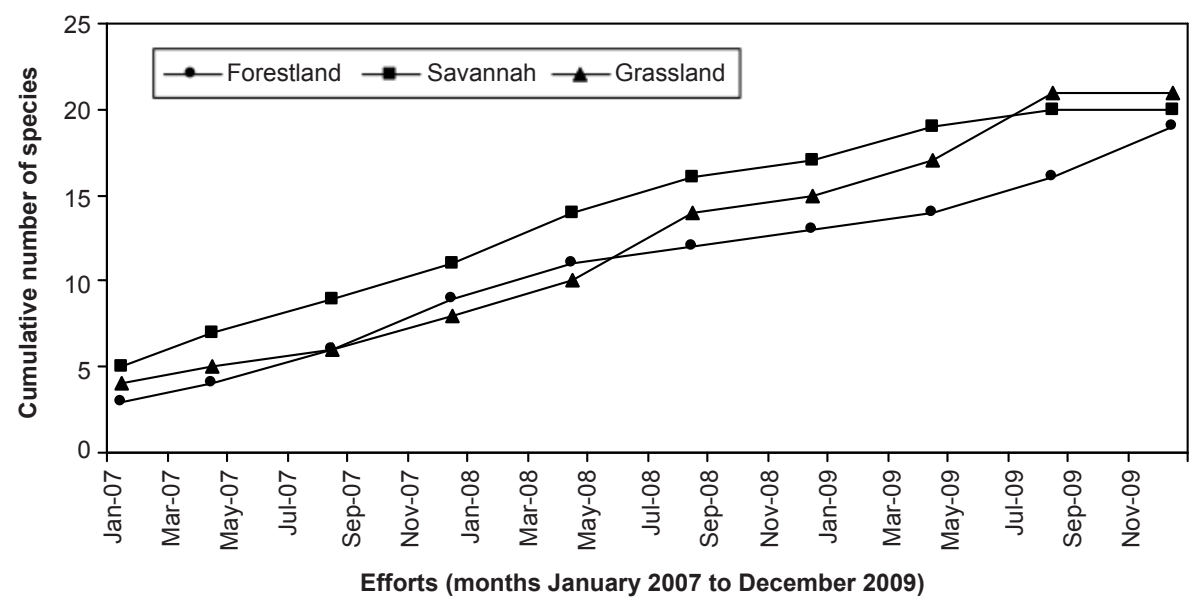

Figure 4. Species accumulation curve of orthopteroids in Kaziranga National Park, Assam

indices $H^{\prime}$, and $\lambda$ appear useful as they incorporate both species richness and evenness into a single value. Shannon's $\left(\mathrm{H}^{\prime}\right)$ diversity index appears to have more value (2.28 to 2.4) (Table 2). The present study indicates that orthopteran species are more diverse in KNP. Distribution of orthopteran species confirmed the log series distribution pattern (Fig. 3) thereby giving creditability to the Fisher's a values. Simpson's diversity index, ' $\lambda$ ', gives high value for grasslands (8.4), followed by savannah (7.56) and the forestland (7.19). 
Table 2. Species diversity indices of orthopteroid fauna in Kaziranga National Park, Assam

\begin{tabular}{|c|c|c|c|c|}
\hline \multicolumn{2}{|c|}{ Indices } & FI & $\mathbf{S}$ & GI \\
\hline \multicolumn{2}{|l|}{ Species richness } & 19 & 20 & 21 \\
\hline \multirow{3}{*}{ Diversity indices } & Alpha $(\alpha)$ & 7.76 & 5.35 & 5.59 \\
\hline & Shannon (H') & 2.28 & 2.35 & 2.4 \\
\hline & Simpson $(\lambda)$ & 7.19 & 7.56 & 8.4 \\
\hline \multirow{2}{*}{ Estimators } & ACE $(\%)$ & 46.54 & 27.26 & 25.6 \\
\hline & ICE (\%) & 35.13 & 30.59 & 25.64 \\
\hline
\end{tabular}

FI - Forestland; S - Savannah; GI - Grassland; ACE - Abundance Based Coverage Estimator; ICE - Incidence Based Coverage Estimators

Since a complete inventorying is impractical, extrapolation techniques are widely employed for estimation of diversity with more intensive sampling. In the present investigation the species accumulation curve did not attain asymptote even after 36 sampling units with monthly intervals. Sanjayan et al. (2002) found that even after 24 sampling efforts (months), the species accumulation curve did not reach asymptote for orthoptera. It is also reflected in the values of the ACE (Abundance based coverage estimator) $(46.54 \%)$ and ICE (Incidence based coverage estimator) (35.13\%). This also indicates the possibility for encountering more species in KNP as against what the mean species accumulation curve depicted (Fig. 4). This study indicates that distribution, diversity and richness of orthopterans in different habitat types of KNP are related to the availability of host plants, subject to the prevailing ecological conditions. It is also important to note that a few species are endemic to Assam, in the eastern sub Himalayas, one of the mega biodiversity hot spots of the world. Therefore Orthopteran faunal diversity of Assam, especially the KNP has to be protected.

\section{REFERENCES}

Chand D.S. \& M.C. Muralirangan (2006). Food consumption of Oxya nitidula (Walker) on different rice cultivars. Journal of Applied Zoological Researches 17: 201-203.

Colwell, R.K. (2004). Estimates, Version 7: Statistical Estimation of Species Richness and Shared Species from Samples. (Software and User's Guide). Freeware for Windows and Mac OS.

Cornell, H.V. \& J.H. Lawton (1992). Species interactions, local and regional processes and limits of the richness of ecological communities: a theoretical perspective. Journal of Animal Ecology 61: 1-12.

Ganeshaiah, K.N., K. Chandrasekara \& A.R.V. Kumar (1997). A new measure of biodiversity based on biological heterogenity of the communities. Current Science 73(2): 128-133.

Ingrisch, S. \& M.S. Shishodia (1997). A new species of Agraecinii from Northeast India. Entomologische Zeitschrift 107(12): 510-512.

Ingrisch, S. \& M.S. Shishodia (1998). New species and records of Tettigoniidae from India (Ensifera). Mitteilungen der
Schweizerischen Entomologischen Gesellschaft 71: 355371.

Ingrisch, S. \& M.S. Shishodia (2000). New taxa and distribution records of Tettigoniidae from India. Mitteilungen Muenchener Entomologischen Gesellschaft 90: 5-37.

IUCN (2010). The 2010 Red List of Threatened Species. http:// www.redlist.org

Ludwig, J.A. \& J.F. Reynolds (1988). Statistical Ecology - $A$ Primer On Methods and Computing. John wiley and sons, Yew York.

Mulkern, G.B. (1967). Food selection by grasshoppers. Annual Review of Entomology 12: 59-78.

Naskrecki, P. (1994). The southern African Mecopodiane their taxonomy, phylogeny and distribution (Orthoptera: Tettigoniidae). Journal of African Zoology 108: 279-320.

Naskrecki, P. (1996a). Systematics of southern African Meconematinae (Orthoptera:Tettigoniidae). Journal of African Zoology 110: 1-28.

Naskrecki, P. (1996b). An interactive key to katydids of La Selva Biological Station. Costa Rica. (http:// viccroy.eeb.uconn. edu/interkey/titlepg)

Naskrecki, P. (2000). Katydids of Costa Rica 1. Systematics and Bioacoustics of The Cone-head Katydids. The Orthopterist Society, USA,163pp.

Rentz, D.C.F. (1979). Comments on the classification of the Orthopteran Family Tettigoniidae, with a key to subfamilies and description of two New subfamilies. Australian Journal of Zoology 27: 991-1013.

Sanjayan, K.P. (1994). Relationship between grasshopper and crops in an agroecosystem of Tamil Nadu, India. Beitraege zur Entomologie 44(1): 232-241.

Sanjayan, K.P., M.C. Murlairangan, N. Senthilkumar \& A. Karthikeyan (2002). Complimentarity and taxic difference estimates and priority analysis for an insight into tettigoniid (Orthoptera: Tettigoniidae) diversity in Chennai, Tamil Nadu. Beitraege zur Entomologie 52(2): 449-460.

Senthilkumar, N., A. Karthikeyan, M.C. Muralirangan, \& V. Mahalingam (2001). Tettigoniidae of Tamil Nadu. Insect Environment 7(2): 56-57.

Senthilkumar, N., A. Karthikeyan, M.C. Muralirangan, V. Mahalingam, \& K.P. Sanjayan (2002). Tettigoniids of Tamil Nadu: A study on biodiversity. Proceedings on the vistas of entomological research for the new millennium, 37-45pp.

Senthilkumar, N., N.D. Barthakur \& N.J. Borah (2006). Orthoptera fauna of the Gibbon Wild Life Sanctuary, Assam, Zoo's Print Journal 21(8): 2347-2349.

Senthilkumar, N., R. Prakash, K.P. Sanjayan, V. Mahalingam \& M.C. Muralirangan (2009). Diversity and distributional pattern of acridids (Orthoptera: Acrididae) in Tamil Nadu, India. Indian Journal of Forestry 32(2): 277-284.

Shishodia, M.S. (2000a). Short and Long-horned grasshoppers and crickets of Bastar District, Madhya Pradesh, India. Records of the Zoological Survey of India 98(1): 27-80.

Shishodia, M.S. (2000b). Orthoptera (Insecta) fauna of Andaman and Nicobar Islands. Records of the Zoological Survey of India 98(3): 1-24.

UNEP-WCMC (2009). Kaziranga National Park, India. In: Cleveland, C.J. (ed.). Encyclopedia of Earth. (Washington, D.C.: Environmental Information Coalition, National Council for Science and the Environment).http://www.eoearth.org/ article/Kaziranga_National_Park,_India 